\title{
Hand-Assisted laparoscopic donor nephrectomy PERiumbilical versus Pfannenstiel incision and return to normal physical ACTivity (HAPERPACT): study protocol for a randomized controlled trial
}

Yakup Kulu', Beat P. Müller-Stich', Omid Ghamarnejad ${ }^{1}$, Elias Khajeh', Georgios Polychronidis ${ }^{1}$, Mohammad Golriz ${ }^{1}$ Felix Nickel', Laura Benner ${ }^{3}$, Philipp Knebel', Markus Diener', Christian Morath², Martin Zeier²,

Markus W. Büchler ${ }^{1}$ and Arianeb Mehrabi ${ }^{1^{*}}$ (D)

\begin{abstract}
Background: Hand-assisted laparoscopic living donor nephrectomy (HALDN) using a periumbilical or Pfannenstiel incision was developed to improve donor outcome after a kidney transplant. The aim of this study was to investigate two methods of hand assistance and kidney removal during HALDN and their effect on the time it takes for the donor to return to normal physical activity.

Methods/design: This study was initiated in November 2017 and is expected to last for 2 years. To be eligible for the study, donors must be more than 20 years of age and must not be receiving permanent pain therapy. Only donors with a single artery and vein in the graft are being enrolled in this trial. Donors with infections or scars in the periumbilical or hypogastric area, bleeding disorders, chronic use of immunosuppressive agents, or active infection will be excluded. Donors will be randomly allocated to either a control arm (periumbilical incision) or an intervention arm (Pfannenstiel incision). The sample size was calculated as 26 organ donors in each group. The primary endpoint is the number of days it takes the donor to return to normal physical activity (up to 4 weeks after the operation). Secondary endpoints are intraoperative outcomes, including estimated blood loss, warm ischemia time, and duration of the operation. Postoperative pain will be assessed using the visual analog scale, rescue analgesic use, and peak expiratory flow rate. Length of hospital stay, physical activity score, time to return to work, donor satisfaction, cosmetic score, postoperative complications, and all-cause mortality in living donors will also be reported. Delayed graft function, primary non-function, serum creatinine levels, and glomerular filtration rate will also be assessed in the recipients after transplantation.
\end{abstract}

Discussion: This is the first randomized controlled trial to compare the time it takes the living donor to return to normal physical activity after HALDN using two different types of incision. The comprehensive findings of this study will help decide which nephrectomy procedure is best for living donors with regard to patient comfort and satisfaction as well as graft function in the recipient after transplantation.

Trial registration: ClinicalTrials.gov, NCT03317184. Registered on 23 October 2017.

Keywords: Living donor, Hand-assisted laparoscopy, Physical activity, Randomized clinical trial

\footnotetext{
* Correspondence: arianeb.mehrabi@med.uni-heidelberg.de

${ }^{1}$ Department of General, Visceral, and Transplantation Surgery, University of

Heidelberg, Im Neuenheimer Feld, 11069120 Heidelberg, Germany

Full list of author information is available at the end of the article
}

(c) The Author(s). 2018 Open Access This article is distributed under the terms of the Creative Commons Attribution 4.0 International License (http://creativecommons.org/licenses/by/4.0/), which permits unrestricted use, distribution, and reproduction in any medium, provided you give appropriate credit to the original author(s) and the source, provide a link to the Creative Commons license, and indicate if changes were made. The Creative Commons Public Domain Dedication waiver (http://creativecommons.org/publicdomain/zero/1.0/) applies to the data made available in this article, unless otherwise stated. 


\section{Background}

Despite remarkable improvements in kidney procurement from deceased donors, the demand for organs is still higher than the number of available kidneys. The use of living donor kidney transplantation (LDKT) has been increased in an attempt to overcome the organ shortage [1-4]. The main concern of LDKT is that a healthy person undergoes major surgery to supply an organ, which may have serious adverse effects. Therefore, a safe nephrectomy method with a low complication rate is just as important as ensuring good graft quality after transplantation $[3,5]$.

Open donor nephrectomy was the most common technique for kidney removal before laparoscopic surgery was developed [6, 7]. Laparoscopic nephrectomy has obvious intraoperative and postoperative advantages over open surgery in terms of blood loss, postoperative pain, duration of hospital stay, and convalescence [8-10]. In 1998, shortly after the development of commercial ports, Wolf et al. [11] reported the hand-assisted laparoscopic living donor nephrectomy (HALDN) technique. Since then, this technique has been widely adopted [12]. HALDN offers better manual control of bleeding, a shorter learning curve, less kidney traction, faster kidney extraction, and shorter warm ischemia times [7, 11-13]. Nowadays, HALDN is one of the most commonly applied surgical procedures, and it has a relatively low complication rate [13].

HALDN is usually performed using a periumbilical or Pfannenstiel incision for hand-port placement and kidney extraction [14]. So far, several retrospective and non-randomized prospective studies have compared periumbilical and Pfannenstiel incisions [13, 15-18]. While some studies have shown better donor outcomes for periumbilical incision with regard to blood loss, warm ischemia time, duration of the surgery, and postoperative pain $[15,17,18]$, Pfannenstiel incision is associated with fewer early and long-term wound complications and better cosmetic outcomes $[13,16]$. Donors were also able to return to work more quickly after a Pfannenstiel incision [15]. However, these conclusions were the results of retrospective or non-randomized prospective studies. To our knowledge, the use of these two different incisions during HALDN has not been compared in a randomized controlled trial (RCT).

In this RCT, we are investigating the effect of two different hand-assistance and kidney removal techniques during HALDN, using periumbilical and Pfannenstiel incisions, on the time it takes for donors to return to normal physical activity. We will also analyze graft function in the recipient after transplantation.

\section{Methods/design}

\section{Setting}

This is a single-center, expert-based RCT. The trial is now underway at the Division of Transplantation Surgery,
Department of General, Visceral, and Transplantation Surgery, University of Heidelberg. It was initiated in November 2017, and it is expected to progress for 2 years. The trial was registered at ClinicalTrials.gov under registration number NCT03317184 on October 23, 2017. The Standard Protocol Items: Recommendations for Interventional Trials (SPIRIT) checklist is provided in Additional file 1.

\section{Patient recruitment}

The study protocol was accepted by the independent Ethics Committee of the University of Heidelberg (registration number S-291/2017). As shown in the study flow chart (Fig. 1), all kidney donors (including left and right kidneys) are currently being screened for eligibility criteria. To be eligible for the study, living donors must be more than 20 years of age and must not be receiving permanent pain therapy. Only donors with a single artery and vein in the graft are being enrolled in this trial. Donors with infections or scars in the periumbilical or hypogastric area, bleeding disorders, chronic use of immunosuppressive agents, and active infection are being excluded. All included donors will be informed about periumbilical and Pfannenstiel incisions for HALDN, as well as their potential benefits and side effects. Eligible donors will receive a written informed consent form. Donors who sign the informed consent form will be included in the study. Reasons for exclusion from the Hand-Assisted laparoscopic donor nephrectomy PERiumbilical versus Pfannenstiel incision and return to normal physical ACTivity (HAPERPACT) trial will be documented and explained in the screening form. After baseline assessments and assessment of eligibility, the patient will be randomized to the periumbilical or Pfannenstiel arm.

\section{Outcome measures}

During the HAPERPACT trial, donors will be monitored before surgery, intraoperatively, on postoperative days (PODs) 1, 2, 3, and at discharge. After discharge, patients will be visited during postoperative weeks (POWs) 2, 4, and 8. During the first four POWs, donors will complete a self-administered questionnaire every day. Demographic and baseline clinical data, intraoperative findings, and postoperative results will be recorded (Fig. 2). Furthermore, graft function will be assessed until the fourth POW.

To enhance participant retention and to avoid loss to follow-up, we call the patients during the follow-up period to remind them of scheduled visits and to arrange appointments. When a patient is not able to participate in a follow-up visit, we will speak with the patient on the telephone and ask him/her to send us a photo of the incision.

\section{Primary endpoint}

Patients will complete the Katz Basic Activities of Daily Living (ADL) self-maintenance questionnaire each day 


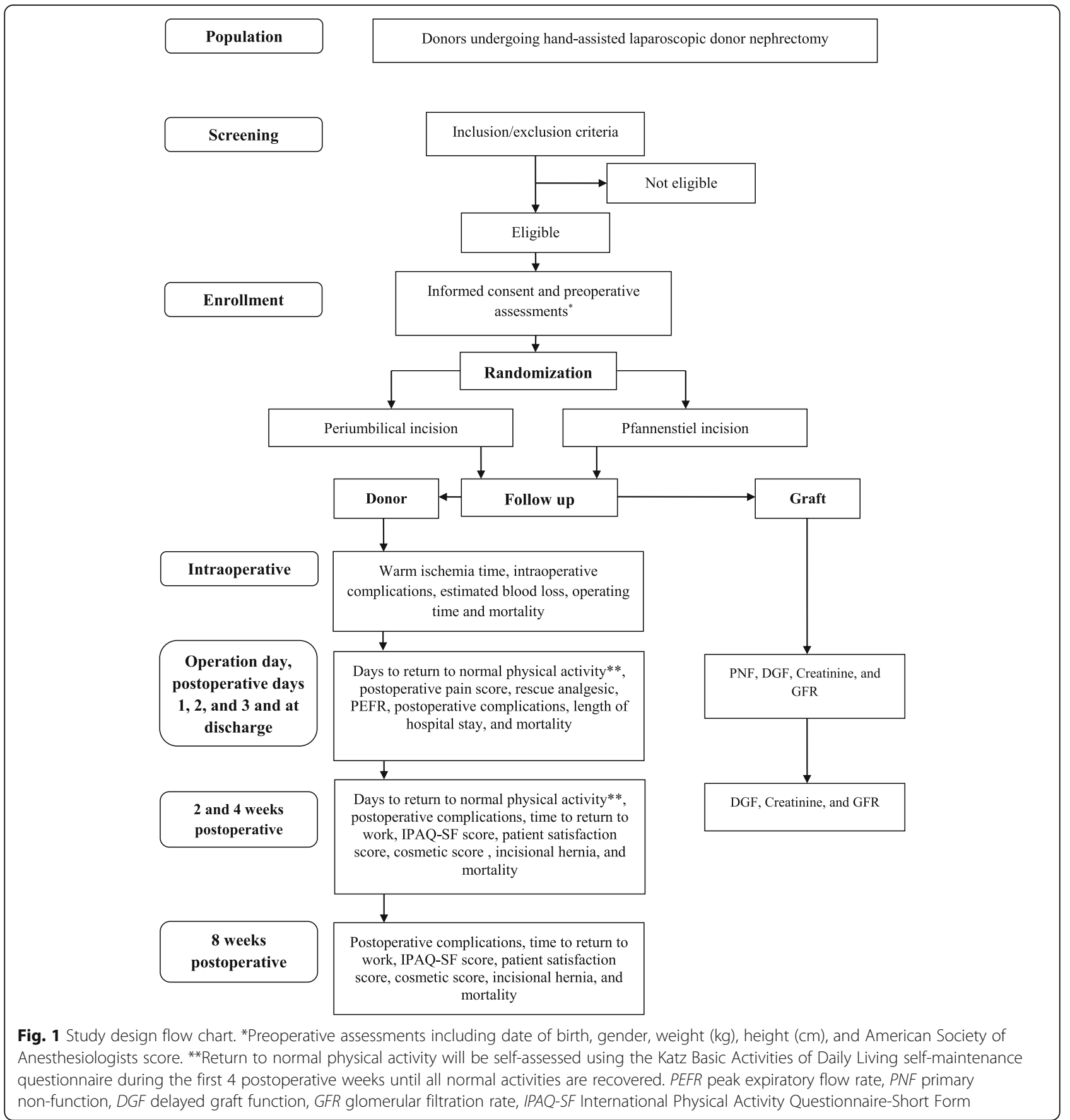

during the first four POWs until all normal activities are recovered. This questionnaire indicates their ability to perform daily living activities [19]. The Katz ADL evaluates the patient's independent performance in six functions: bathing, dressing, using the toilet, transferring, continence, and feeding. These functions are evaluated with yes/no questions. A score of 6 indicates independence in all six functions, demonstrating normal physical activity. Since all donors are able to perform these basic activities before the operation, the Katz ADL questionnaires are not administered prior to surgery. The questionnaires will be gathered at each follow-up visit, and the number of days it takes to return to normal physical activity will be determined based on the answers. The primary endpoint has been defined as the number of days from surgery until return to normal physical activity.

\section{Secondary endpoints}

Intraoperative outcomes, including estimated blood loss, warm ischemia time, and operating time, will be reported. 


\begin{tabular}{|c|c|c|c|c|c|c|c|c|c|}
\hline \multirow[b]{3}{*}{ TIMEPOINT } & \multicolumn{9}{|c|}{ STUDY PERIOD } \\
\hline & \multirow{2}{*}{$\begin{array}{c}\text { Enrolment } \\
\begin{array}{c}\text { Administrati } \\
\text { on day }\end{array} \\
\end{array}$} & \multirow{2}{*}{$\begin{array}{c}\text { Interventi } \\
\text { on }\end{array}$} & \multicolumn{6}{|c|}{ Post-allocation } & \multirow{2}{*}{\begin{tabular}{|c|}
$\begin{array}{c}\text { Close } \\
\text {-out }\end{array}$ \\
POW \\
8 \\
\end{tabular}} \\
\hline & & & $\begin{array}{l}P O \\
D 1\end{array}$ & $\begin{array}{l}\mathrm{PO} \\
\mathrm{D} 2\end{array}$ & $\begin{array}{l}P O \\
D 3\end{array}$ & $\begin{array}{c}\text { Dischar } \\
\text { ge }\end{array}$ & $\begin{array}{l}\mathrm{PO} \\
\mathrm{W} 2\end{array}$ & $\begin{array}{l}P O \\
W 4\end{array}$ & \\
\hline \multicolumn{10}{|l|}{ ENROLMENT: } \\
\hline Eligibility screen & $\mathrm{X}$ & & & & & & & & \\
\hline Informed consent & $\mathrm{X}$ & & & & & & & & \\
\hline Randomization & $\mathrm{X}$ & & & & & & & & \\
\hline Allocation & $\mathrm{X}$ & & & & & & & & \\
\hline \multirow{3}{*}{$\begin{array}{l}\text { INTERVENTIO } \\
\text { NS: } \\
\text { HALDN using } \\
\text { periumbilical } \\
\text { HALDN using } \\
\text { Pfannenstiel } \\
\end{array}$} & & & & & & & & & \\
\hline & & $\mathrm{x}$ & & & & & & & \\
\hline & & $\mathrm{x}$ & & & & & & & \\
\hline \multicolumn{10}{|l|}{ ASSESSMENTS: } \\
\hline \multirow{4}{*}{$\begin{array}{l}\text { Baseline } \\
\text { assessments }^{\mathrm{a}} \\
\text { Warm ischemia } \\
\text { time } \\
\text { Intraoperative } \\
\text { complications } \\
\text { Estimated blood } \\
\text { loss }\end{array}$} & $\mathrm{x}$ & & & & & & & & \\
\hline & & $\mathrm{x}$ & & & & & & & \\
\hline & & $\mathrm{X}$ & & & & & & & \\
\hline & & $\mathrm{x}$ & & & & & & & \\
\hline Operating time & & $\mathrm{x}$ & & & & & & & \\
\hline \multirow{3}{*}{$\begin{array}{l}\text { Days to return to } \\
\text { normal physical } \\
\text { activity } \\
\text { Postoperative pain } \\
\text { score } \\
\text { Rescue analgesic }\end{array}$} & & & & & & & & & \\
\hline & & & $\mathrm{x}$ & $\mathrm{x}$ & $\mathrm{X}$ & $\mathrm{X}$ & & & \\
\hline & & & $\mathrm{X}$ & $\mathrm{X}$ & $\mathrm{X}$ & $\mathrm{X}$ & & & \\
\hline \multirow{4}{*}{$\begin{array}{l}\text { Peak expiratory } \\
\text { flow rate } \\
\text { Postoperative } \\
\text { complications } \\
\text { Length of hospital } \\
\text { stay } \\
\text { Time to return to } \\
\text { work }\end{array}$} & $\mathrm{x}$ & & $\mathrm{x}$ & $\mathrm{x}$ & $\mathrm{x}$ & $\mathrm{x}$ & & & \\
\hline & & & $\mathrm{X}$ & $\mathrm{x}$ & $\mathrm{x}$ & $\mathrm{X}$ & $\mathrm{X}$ & $\mathrm{X}$ & $\mathrm{X}$ \\
\hline & & & $\mathrm{x}$ & $\mathrm{x}$ & $\mathrm{x}$ & $\mathrm{x}$ & & & \\
\hline & & & & & & & $\mathrm{x}$ & $\mathrm{x}$ & $\mathrm{x}$ \\
\hline \multirow{2}{*}{$\begin{array}{l}\text { IPAQ-SF score } \\
\text { Patient satisfaction } \\
\text { score }\end{array}$} & $\mathrm{x}$ & & & & & & $\mathrm{x}$ & $\mathrm{x}$ & $\mathrm{X}$ \\
\hline & & & & & & & $\mathrm{X}$ & $\mathrm{X}$ & $\mathrm{X}$ \\
\hline Cosmetic score & & & & & & & $\mathrm{X}$ & $\mathrm{X}$ & $\mathrm{X}$ \\
\hline Incisional hernia & & & & & & & $\mathrm{X}$ & $\mathrm{X}$ & $\mathrm{X}$ \\
\hline \multirow{2}{*}{$\begin{array}{l}\text { Mortality } \\
\text { Primary non- } \\
\text { function }\end{array}$} & & $\mathrm{x}$ & $\mathrm{X}$ & $\mathrm{X}$ & $\mathrm{X}$ & $\mathrm{X}$ & $\mathrm{X}$ & $\mathrm{x}$ & $\mathrm{X}$ \\
\hline & & & $\mathrm{x}$ & $\mathrm{x}$ & $\mathrm{x}$ & $\mathrm{X}$ & $\mathrm{X}$ & $\mathrm{x}$ & \\
\hline \multirow{4}{*}{$\begin{array}{l}\text { Delayed graft } \\
\text { function } \\
\text { Recipient serum } \\
\text { creatinine level } \\
\text { Glomerular } \\
\text { filtration rate } \\
\text { Safty assessment } \\
\end{array}$} & & & $\mathrm{x}$ & $\mathrm{x}$ & $\mathrm{x}$ & $\mathrm{x}$ & $\mathrm{x}$ & $\mathrm{x}$ & \\
\hline & & & $\mathrm{x}$ & $\mathrm{x}$ & $\mathrm{x}$ & $\mathrm{X}$ & $\mathrm{x}$ & $\mathrm{x}$ & \\
\hline & & & $\mathrm{X}$ & $\mathrm{X}$ & $\mathrm{X}$ & $\mathrm{X}$ & $\mathrm{X}$ & $\mathrm{x}$ & \\
\hline & & $\mathrm{X}$ & $\mathrm{X}$ & $\mathrm{X}$ & $\mathrm{X}$ & $\mathrm{X}$ & $\mathrm{X}$ & $\mathrm{X}$ & $\mathrm{X}$ \\
\hline
\end{tabular}

Fig. 2 HAPERPACT trial design according to the Standard Protocol Items: Recommendations for Interventional Trials (SPIRIT) checklist 
In addition to the Katz ADL questionnaire, a physical activity score will be determined using the International Physical Activity Questionnaire-Short Form (IPAQ-SF). The IPAQ-SF score will be calculated before the operation and at POWs 2, 4, and 8. Postoperative pain will be assessed using the visual analog scale (VAS $0-10,0=$ no pain and $10=$ unbearable distress) and by measuring in-hospital rescue analgesics until discharge. The peak expiratory flow rate (PEFR) will also be evaluated preoperatively and until discharge as an objective surrogate measure of pain. Length of hospital stay, time to return to work, postoperative complications, and all-cause mortality will also be reported in living donors. The appearance of incision scars will be evaluated with a patient satisfaction score (Likert scale $1-5$, with 5 indicating strongly satisfied and 1 indicating strongly unsatisfied) and a cosmetic score (defined by the Stony Brook Scar Evaluation Scale [20]) during the first eight POWs. Possible incisional hernia at the site of the surgical incision will be examined by palpation and ultrasonography during each visit. The quality of the procured graft will also be evaluated in recipients after both procedures. Delayed graft function, primary non-function, serum creatinine levels, and glomerular filtration rates will be assessed in recipients until POW 4. Secondary outcome measures are defined in Table 1.

\section{Standardized therapy and trial interventions}

The site of hand-port placement will be randomized. All other intraoperative and perioperative treatments are standardized procedures. Prophylactic antibiotic therapy and use of intravenous or oral analgesic agents to relieve postoperative pain will be administered according to our kidney transplantation manual [21].

According to the randomization arm, hand-port placement and hand insertion will be via a midline periumbilical or Pfannenstiel incision. HALDN with a periumbilical incision will be performed by positioning the donor in a left/right lateral decubitus position. A 5 -mm laparoscope port will be placed at the midclavicular line in the left/right upper quadrant (two finger breadths below the costal margin), and one working instrument $(12 \mathrm{~mm})$ will be placed at the level of the umbilicus to the left/right of the midline. HALDN with a

Table 1 Secondary endpoints of the HAPERPACT trial

\begin{tabular}{|c|c|}
\hline Secondary endpoints & Definitions \\
\hline Warm ischemia time & $\begin{array}{l}\text { From the time of clamping the first renal artery in situ to flushing the kidney with chilled solution on } \\
\text { the back table (minutes) }\end{array}$ \\
\hline Intraoperative complications & Any complication occurring during the operation \\
\hline Estimated blood loss & The entire blood loss from skin incision to skin closure (milliliters) \\
\hline Operating time & From the time of skin incision to closure of the skin incision (minutes) \\
\hline Postoperative pain & Severity of pain measured by the 11 -point visual analog scale ( $0=$ no pain and $10=$ unbearable distress) \\
\hline Rescue analgesic & Total amount of analgesics required during the first three postoperative days \\
\hline Peak expiratory flow rate (PEFR) & Maximum speed of expiration, measured with a peak flow meter \\
\hline Postoperative complications & $\begin{array}{l}\text { Postoperative surgical complications (i.e., burst abdomen and hernia, wound infection, seroma, and hematoma, } \\
\text { intra-abdominal bleeding/hematoma, intra-abdominal abscess or collection, lymphocele, and postoperative ileus) } \\
\text { and medical complications (pneumonia, pleural effusion, urinary tract infection). Each complication will be graded } \\
\text { according to the Clavien-Dindo classification [29] }\end{array}$ \\
\hline Length of hospital stay & From the day of the operation until the day of discharge (days) \\
\hline Time to return to work & The number of days from discharge to return to work \\
\hline IPAQ-SF score* & $\begin{array}{l}\text { The physical activity of patients will be evaluated preoperatively, and on postoperative weeks } 1,2,4 \text {, and } 8 \text { using } \\
\text { the IPAQ-SF [18] }\end{array}$ \\
\hline Patient satisfaction score & Patient satisfaction score measured by the 5 -point Likert scale $(5=$ strongly satisfied and $1=$ strongly unsatisfied) \\
\hline Cosmetic score & Cosmetic score as defined by the Stony Brook Scar Evaluation Scale [20] \\
\hline Incisional hernia & $\begin{array}{l}\text { Fascia or muscle defect (bulging hernial sac and palpable fascia gap) at the site of the surgical incision examined } \\
\text { by palpation and ultrasonography }\end{array}$ \\
\hline Mortality & Death due to any cause at any time during the follow-up period \\
\hline Primary non-function (PNF) & The graft never functions \\
\hline Delayed graft function (DGF) & $\begin{array}{l}\text { The need for one or more hemodialysis treatments following transplantation prior to the onset of graft function. } \\
\text { The duration of DGF will be calculated from the date of transplantation to the date of the last dialysis treatment }\end{array}$ \\
\hline Recipient serum creatinine level & Serum creatinine level (mg/dL) \\
\hline Glomerular filtration rate (GFR) & $\mathrm{GFR}\left(\mathrm{mL} / \mathrm{min} / 1.73 \mathrm{~m}^{2}\right)$ calculated as $175 \times\left(\mathrm{S}_{\mathrm{cr}}\right)^{-1.154} \times(\text { Age })^{-0.203} \times(0.742$ if female $)$ \\
\hline
\end{tabular}


Pfannenstiel incision will be performed by placing the donor in the French position. A four-port transperitoneal approach will be used: a 10-mm umbilical trocar for the laparoscope, one $5-\mathrm{mm}$ port in the midline, one 12-mm port at the level of the umbilicus to the left/right of the midline, and an additional 5-mm port will be inserted at the left/right border of the Pfannenstiel incision. As soon as the blood vessels are divided and the nephrectomy is completed, the graft will be extracted using the hand port. At the end of the operation, an abdominal drain will be placed and the wound will be closed.

\section{Modification of the protocol}

Protocol amendments will be considered by the principal investigator after feedback from the Clinical Trial Center. All protocol amendments will be submitted to the Ethics Committee for approval. No further recruitments will take place until the modifications are accepted.

\section{Assessment of safety and termination criteria}

To assess the safety of the periumbilical and Pfannenstiel approaches, serious adverse events (SAEs) will be observed and evaluated. Only intervention-related events that occur during surgery and follow-up will be documented. At each visit, the physician will ask the donor if he/she has suffered from any SAEs since the last visit. The attending physician must tell the principal investigator about any reported SAEs within $24 \mathrm{~h}$. The report will be complete and include details of the SAE and whether the SAE was caused by the trial treatment. All intervention-related SAEs will be documented and analyzed.

Donors will be excluded from the study if they withdraw their consent to participate in the trial. A donor may withdraw consent at any time without explanation and without affecting further medical care. The principal investigator may terminate the trial at any time in consultation with the key research associates and the biostatistician. Possible reasons for termination include high morbidity or mortality rates and any indication of potential health hazards caused by either the study treatment or external factors.

\section{Randomization and blinding}

Donors will be randomized to the different groups using the block randomization method. Each block contains two groups of periumbilical and Pfannenstiel incisions. The block size is hidden from the trial executers and clinicians. Possible balanced combinations of these groups within the block are numbered consecutively. Then, blocks are randomly chosen using simple randomization software (Microsoft Excel ${ }^{\circ}$ ), and a series of randomly assigned periumbilical and Pfannenstiel incisions are generated based on the random sequence of blocks. Allocation will be concealed using sequentially numbered, sealed opaque envelopes prepared by a member of our Clinical Trial Center. Donors will be randomly allocated to either the control arm (periumbilical incision, Group A), or the intervention arm (Pfannenstiel incision, Group B) a day before surgery. The trial executors receive randomly generated treatment allocations within sealed opaque envelopes. Afterwards, medical staff will personally inform the expert surgeon as to which treatment group the patient has been randomized. To avoid any potential prediction of group allocation, information on the block length will be kept away from the study site.

After the operation, the periumbilical and hypogastric regions will be covered with a double wound dressing until discharge. During this period, the severity of pain, rescue analgesic, and PEFR will be evaluated by anesthesiologists blinded to the incision type. Participants will also be blinded to the incision type. If blinding could affect the patient's treatment, for example in the case of a medical emergency or serious medical condition, then the participant/assessor will be unblinded. After POD 4, a nephrologist who is unaware of the study will evaluate and document the primary and secondary endpoints of the trial. At the end of the trial, the data management center will receive all sealed envelopes and will check the accuracy of randomization numbers.

\section{Data management}

All data will be collected and recorded in case report forms (CRFs) by an investigator before transfer to the data management center. To ensure accurate data collection, after each patient has been visited, the CRF will be completed by an investigator who did not evaluate the patient. All demographic and baseline clinical data, as well as primary and secondary outcome measures, will be recorded in the CRF. All data will be checked, and any missing data will be obtained from the trial database or from participants. To ensure patient confidentiality, the CRF for each patient will be given an anonymous allocation number. We will obtain permission to continue follow-up and data collection in the event of withdrawal from the study. The responsible investigator must review and sign all completed CRFs. Afterwards, data will be statistically analyzed by a statistician who is unaware of the allocated treatment.

\section{Statistical methods Sample size}

The null hypothesis is that Pfannenstiel incision is not superior to periumbilical incision in terms of the average number of days it takes the donor to return to normal physical activity in the 4 weeks after surgery. We chose 10 days difference in return to normal physical activity as the minimal clinically important difference, because a difference of less than 10 days is not valuable enough to 
decide the standard surgical method. Therefore, we used a difference of 10 days for sample size calculation. The standard deviation is expected to be 13 days, according to the results of El-Galley et al. [15], who compared days to return to work between periumbilical and Pfannenstiel incision groups. However, we chose "days to return to normal physical activity" as the primary endpoint rather than "days to return to work" because the nature of patients' work and their capabilities are different, and some of our living donors may be unemployed or housekeepers. A one-sided significance level of $\alpha=0.05$, a power of $80 \%$, and a sample size of 44 patients ( 22 per group) are required to apply a two-sample $t$ test (calculations performed with AddPlan 6.0). To account for a $15 \%$ drop-out rate, 26 patients will be enrolled in each study arm (52 patients in total).

\section{Statistical analysis}

The primary endpoint is the number of days from surgery to return to normal physical activity. This will be assessed using the Katz ADL questionnaire. The primary analysis will test the following hypotheses:

$$
\begin{aligned}
& \mathrm{H}_{0} \mu_{\text {Pfannenstiel }} \geq \mu_{\text {Periumbilical }} \\
& \mathrm{H}_{1} \mu_{\text {Pfannenstiel }}<\mu_{\text {Periumbilical }},
\end{aligned}
$$

where $\mu_{\text {Pfannenstiel }}$ and $\mu_{\text {Periumbilical }}$ are the mean number of days in the respective intervention groups. The primary endpoint will be compared between the intervention groups using a Student's $t$ test and a one-sided significance level of $5 \%$. Additionally, a Mann-Whitney $U$ test will be performed for sensitivity analysis. According to the intention-to-treat approach, all patients will be analyzed in the group to which they were randomized.

All secondary outcomes will be analyzed using appropriate summary measures depending on the distribution of the data and descriptive $p$ values. Categorical data will be presented as absolute and relative frequencies. Continuous data will be presented as mean values with standard deviations and by median values with interquartile ranges, minimum values, and maximum values. Statistical analysis will be performed using SPSS version 24.0 (SPSS, Inc., Chicago, IL, USA). A statistical analysis plan will be developed by the principal investigator by the end of recruitment.

\section{Discussion}

LDKT is one of the best solutions for organ shortage. Since living kidney donors give others a second chance to live, it is very important that they undergo the safest possible surgical procedure with the lowest risk and complication rate. Although both HALDN procedures (periumbilical and Pfannenstiel) are accepted surgical approaches [22-25], these two different incision methods have not been compared in an RCT. This RCT was initiated to compare the outcome of periumbilical and Pfannenstiel incisions.
Only one RCT has compared HALDN using a periumbilical incision with pure laparoscopic donor nephrectomy using a Pfannenstiel incision for graft extraction [26]. The authors compared operation time, warm ischemia time, complications, and quality of life between the two groups, but they did not report the time it took for the donor to return to work/normal physical activity or wound appearance. This RCT also compared two different methods (pure laparoscopy versus HALDN) as well as two types of incision. There are also some published non-randomized or retrospective studies that compare periumbilical and Pfannenstiel incisions for hand assistance and/or kidney removal in HALDN or laparoscopic donor nephrectomy [15-18]. However, although El-Galley et al. [15] reported the time to return to normal activity and work, none of these studies evaluated the donor's comfort and satisfaction; they mainly compared the occurrence of complications and length of hospital stay after the two procedures.

The HAPERPACT trial will be the first RCT to evaluate the impact of periumbilical and Pfannenstiel incisions on donor recovery. We will compare the time it takes for the donor to return to normal physical activity after the two different procedures. This will indicate patient satisfaction and comfort, as well as the influence on economy and burden of disease.

The secondary findings of this RCT will compare the intraoperative and postoperative results in living kidney donors. The HAPERPACT trial is novel in that it investigates all factors associated with donor satisfaction after nephrectomy, including postoperative pain, rescue analgesics, PEFR, physical activity (using IPAQ), length of hospital stay, time to return to work, patient satisfaction, and cosmetic score. To ensure that our findings are more encyclopedic, the quality of the transplanted graft and graft function in recipients will also be monitored in this trial.

One limitation of this RCT is that the primary endpoint cannot be evaluated blind. However, some early outcome measures will be evaluated double blindly (participant and assessor blinded) until discharge by covering both periumbilical and hypogastric areas using double wound dressing. Furthermore, to prevent bias in further assessments, all follow-up visits will be performed by a nephrologist who is unaware of the study. Another limitation is that the primary outcome of this RCT is a subjective, self-maintenance measure. However, results of the Katz ADL self-administered questionnaire are known to be valid and reliable [27]. In addition to the Katz ADL questionnaire, we will also use the established IPAQ-SF [28], which will be completed by the investigator before and after surgery. There is no data monitoring process in the HAPERPACT trial, because the methods used are both standard surgical procedures for living donor nephrectomy and also because the biggest part of documentation in this trial is 
the standard clinical follow-up of the patients. Therefore, a data monitoring committee is dispensable in this trial.

In summary, published retrospective and non-randomized prospective studies have not clarified the advantages and disadvantages of periumbilical versus Pfannenstiel incisions in HALDN. The HAPERPACT trial will be the first RCT to compare the outcome of HALDN using two different types of incision. The comprehensive findings of this study may help to decide the optimal nephrectomy procedure for earlier return to normal physical activity, comfort, and satisfaction in donors as well as graft function in recipients.

\section{Trial status}

The HAPERPACT trial is currently recruiting participants.

\section{Additional file}

Additional file 1: SPIRIT checklist. (DOC $123 \mathrm{~kb}$ )

\section{Abbreviations}

ADL: Activities of daily living; CRF: Case report form; DGF: Delayed graft function; GFR: Glomerular filtration rate; HALDN: Hand-assisted laparoscopic living donor nephrectomy; IPAQ-SF: International Physical Activity Questionnaire-Short Form; LDKT: Living donor kidney transplantation; PEFR: Peak expiratory flow rate; PNF: Primary non-function; POD: Postoperative day; POW: Postoperative week; RCT: Randomized controlled trial; SAE: Serious adverse event; VAS: Visual analog scale

\section{Acknowledgements}

The authors gratefully thank the members of the Clinical Trial Center of the Department of General, Visceral, and Transplantation Surgery, University of Heidelberg for their support in performing this RCT.

\section{Funding}

This research received no specific funding agency in the public, commercial, or not-for-profit sectors.

\section{Authors' contributions}

$A M, Y K$, and BPMS developed the original concept of the trial. AM, YK, OG, $E K$, and MG developed the design and methodology. EK, FN, and LB performed the statistical assessments and developed the analysis plan. EK, $O G, M G$, and GP contributed to drafting the protocol of the paper and the article. YK, BPMS, PK, MD, CM, MZ, MWB, and AM contributed to the revision of the final report. All authors read and approved the final manuscript.

\section{Ethics approval and consent to participate}

This protocol study received approval from the Ethics Committee of the University of Heidelberg (registration number S-291/2017). All living donors receive clarifications regarding the objectives and procedures, and written informed consent will be obtained from those who agree to participate.

\section{Consent for publication}

Written informed consent for publication of the clinical images will be obtained from the patient.

\section{Competing interests}

The authors declare that they have no competing interests.

\section{Publisher's Note}

Springer Nature remains neutral with regard to jurisdictional claims in published maps and institutional affiliations.

\section{Author details}

'Department of General, Visceral, and Transplantation Surgery, University of Heidelberg, Im Neuenheimer Feld, 11069120 Heidelberg, Germany. ${ }^{2}$ Department of Nephrology, Heidelberg University Hospital, Heidelberg, Germany. ${ }^{3}$ Institute of Medical Biometry and Informatics, University of Heidelberg, Heidelberg, Germany.

Received: 1 February 2018 Accepted: 29 June 2018

Published online: 13 July 2018

\section{References}

1. Abecassis M, Bartlett ST, Collins AJ, Davis CL, Delmonico FL, Friedewald JJ, Hays R, Howard A, Jones E, Leichtman AB. Kidney transplantation as primary therapy for end-stage renal disease: a National Kidney Foundation/Kidney Disease Outcomes Quality Initiative (NKF/KDOQI ${ }^{\mathrm{TM}}$ ) conference. Clin J Am Soc Nephrol. 2008;3:471-80.

2. Smith CR, Woodward RS, Cohen DS, Singer GG, Brennan DC, Lowell JA, Howard TK, Schnitzler MA. Cadaveric versus living donor kidney transplantation: a medicare payment analysis 1. Transplantation. 2000;69:311.

3. Mehrabi A, Wiesel M, Zeier M, Kashfi A, Schemmer P, Kraus T, Buchler MW Schmidt J. Results of renal transplantation using kidneys harvested from living donors at the University of Heidelberg. Nephrol Dial Transplant. 2004; 19(Suppl 4):iv48-54.

4. Fonouni $H$, Golriz M, Mehrabi A, Oweira H, Schmied BM, Muller SA, Jarahian P, Tahmasbi Rad M, Esmaeilzadeh M, Tonshoff B, et al. The role of an interdisciplinary transplant team on living donation kidney transplantation program. Transplant Proc. 2010;42:137-40.

5. Weitz J, Koch M, Mehrabi A, Schemmer P, Zeier M, Beimler J, Buchler M, Schmidt J. Living-donor kidney transplantation: risks of the donor-benefits of the recipient. Clin Transpl. 2006;20(Suppl 17):13-6.

6. Ratner LE, Ciseck L, MooRE RG, Cigarroa F, Kaufman HS, Kavoussi L. Laparoscopic live donor nephrectomy. Transplantation. 1995;60:1047-9.

7. Flowers $\mathrm{L}$, Jacobs S, Cho E, Morton A, Rosenberger WF, Evans D, Imbembo $\mathrm{AL}$, Bartlett ST. Comparison of open and laparoscopic live donor nephrectomy. Ann Surg. 1997;226:483.

8. Merlin TL, Scott DF, Rao MM, Wall DR, Francis DM, Bridgewater FH, Maddern GJ. The safety and efficacy of laparoscopic live donor nephrectomy: a systematic review. Transplantation. 2000;70:1659-66.

9. Rajab A, Mahoney JE, Henry ML, Elkhammas EA. Hand-assisted laparoscopic versus open nephrectomies in living donors. Can J Surg. 2005;48:123.

10. Fonouni H, Mehrabi A, Golriz M, Zeier M, Muller-Stich BP, Schemmer P, Werner J. Comparison of the laparoscopic versus open live donor nephrectomy: an overview of surgical complications and outcome. Langenbeck's Arch Surg. 2014:399:543-51.

11. Wolf JS, Tchetgen M-B, Merion RM. Hand-assisted laparoscopic live donor nephrectomy. Urology. 1998;52:885-7.

12. Velidedeoglu E, Williams N, Brayman KL, Desai NM, Campos L, Palanjian M, Wocjik M, Bloom R, Grossman RA, Mange K. Comparison of open, laparoscopic, and hand-assisted approaches to live-donor nephrectomy. Transplantation. 2002;74:169-72.

13. Serrano OK, Kirchner V, Bangdiwala A, Vock DM, Dunn TB, Finger EB, Payne WD, Pruett TL, Sutherland DE, Najarian JS, et al. Evolution of living dono nephrectomy at a single center: long-term outcomes with 4 different techniques in greater than 4000 donors over 50 years. Transplantation. 2016:100:1299-305.

14. Rajab A, Pelletier RP. The safety of hand-assisted laparoscopic living donor nephrectomy: the Ohio State University experience with 1500 cases. Clin Transpl. 2015;29:204-10.

15. El-Galley R, Hood N, Young CJ, Deierhoi M, Urban DA. Donor nephrectomy: a comparison of techniques and results of open, hand assisted and full laparoscopic nephrectomy. J Urol. 2004;171:40-3.

16. Gwon JG, Jun H, Kim MG, Boo YJ, Jung CW. Comparative outcomes of hand-assisted laparoscopic donor nephrectomy using midline incision or low transverse incision for hand-assisted port placement. Exp Clin Transplant. 2016;14:282-6.

17. Gershbein AB, Fuchs GJ. Hand-assisted and conventional laparoscopic live donor nephrectomy: a comparison of two contemporary techniques. J Endourol. 2002;16:509-13.

18. Lindström P, Häggman M, Wadström J. Hand-assisted laparoscopic surgery (HALS) for live donor nephrectomy is more time-and cost-effective than standard laparoscopic nephrectomy. Surg Endosc. 2002;16:422-5. 
19. Katz S. Assessing self-maintenance: activities of daily living, mobility, and instrumental activities of daily living. J Am Geriatr Soc. 1983;31:721-7.

20. Singer AJ, Arora B, Dagum A, Valentine S, Hollander JE. Development and validation of a novel scar evaluation scale. Plast Reconstr Surg. 2007;120:1892-7.

21. Beimler J, Schmidt J, Büchler M, Zeier M. Heidelberger Manual der Nieren- und Pankreastransplantation. Heidelberg: Ruprecht-Karls-Universität Heidelberg; 2007

22. Shohab D, Jamil I, Khan IA, Khawaja MA, Khan MA, Akhter S. Hand-assisted laparoscopic donor nephrectomy: a single-center study. Saudi J Kidney Dis Transpl. 2017;28:661-3.

23. Lim J, Kong YG, Kim YK, Hong B. Risk factors associated with decreased renal function after hand-assisted laparoscopic donor nephrectomy: a multivariate analysis of a single surgeon experience. Int J Med Sci. 2017;14:159-66.

24. Elmaraezy A, Abushouk Al, Kamel M, Negida A, Naser O. Should hand-assisted retroperitoneoscopic nephrectomy replace the standard laparoscopic technique for living donor nephrectomy? A meta-analysis. Int J Surg. 2017:40:83-90.

25. Wiborg MH, Toft A, Jahn H, Hansen LU, Lund L. Initial experience with hand-assisted laparoscopic donor nephrectomy: a single-centre experience over 5 years. Scand J Urol. 2017;51:73-7.

26. Bargman V, Sundaram CP, Bernie J, Goggins W. Randomized trial of laparoscopic donor nephrectomy with and without hand assistance. J Endourol. 2006;20:717-22.

27. Ferretti-Rebustini RE, Balbinotti MA, Jacob-Filho W, Rebustini F, Suemoto CK Pasqualucci CA, Farfel JM, Leite RE, Grinberg LT, Nitrini R. Validity of the Katz Index to assess activities of daily living by informants in neuropathological studies. Rev Esc Enferm USP. 2015;49:946-52.

28. Lee PH, Macfarlane DJ, Lam TH, Stewart SM. Validity of the International Physical Activity Questionnaire Short Form (IPAQ-SF): a systematic review. Int J Behav Nutr Phys Act. 2011;8:115.

29. Dindo D, Demartines N, Clavien P-A. Classification of surgical complications: a new proposal with evaluation in a cohort of 6336 patients and results of a survey. Ann Surg. 2004;240:205-13.

\section{Ready to submit your research? Choose BMC and benefit from:}

- fast, convenient online submission

- thorough peer review by experienced researchers in your field

- rapid publication on acceptance

- support for research data, including large and complex data types

- gold Open Access which fosters wider collaboration and increased citations - maximum visibility for your research: over $100 \mathrm{M}$ website views per year

At BMC, research is always in progress.

Learn more biomedcentral.com/submissions 